\title{
EL ARTÍCULO 6 DE LA LEY 10.432. MAS ALLA DE LAS PRERROGATIVAS OTORGADAS POR LA LEY NACIONAL REGISTRAL ${ }^{1}$
}

\author{
ARTICLE 6 OF LAW 10.432. BEYOND THE PREROGATIVES GRANTED BY THE \\ NATIONAL REGISTRY LAW
}

Por Federico A. Contreras ${ }^{(*)}$

\begin{abstract}
Resumen: Este trabajo se estructura sobre el análisis de la norma provincial Nro. 10.432, la cual en post de actualizar y modernizar el sistema procedió fijar como el plazo de los certificados notariales en un plazo único y genérico de 30 días, a tales fines se analiza el principio registral de prioridad, sus impactos, la reserva de prioridad y la determinación e impacto de los plazos de vigencia del certificado. Se contrapone la normativa provincial con la nacional y se analizan los posibles planteos de inconstitucionalidad que podrían darse.
\end{abstract}

Palabras claves: Principios registrales - certificado registral - principio de inscripción

\begin{abstract}
This work is structured on the analysis of provincial norm No. 10432, which after updating and modernizing the system proceeded to set as the term of notarial certificates in a single and generic term of 30 days, for such purposes the Priority registration principle, its impacts, priority reservation and the determination and impact of the validity periods of the certificate. The provincial regulation is contrasted with the national one and the possible unconstitutionality issues that could occur are analyzed.
\end{abstract}

Keywords: Registration principles - registration certificate - principle of registration

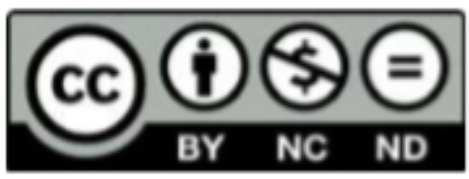

Artículo publicado bajo Licencia Creative Commons Atribución-No Comercial-Sin

Derivar. (C) Universidad Católica de Córdoba

DOI http://dx.doi.org/10.22529/adc.2019(13)06

\footnotetext{
${ }^{1}$ Artículo recibido el 15 de agosto y aprobado para su publicación el 10 de noviembre de 2019.

(*) *Abogado (UNC) - Escribano (UE21). Mail: fedecontrerass@ gmail.com
} 


\section{EL ARTÍCULO 6 DE LA LEY 10.432. MAS ALLA DE LAS PRERROGATIVAS OTORGADAS POR LA LEY NACIONAL REGISTRAL}

\section{1) INTORDUCCIÓN.}

Como ya todos sabemos, grandes fueron los esfuerzos para lograr una mayor celeridad en el tráfico jurídico inmobiliario. Así el Estado Provincial a través de distintas leyes, como por ejemplo la ley $\mathrm{N}^{\circ} 8835$-Carta al Ciudadano- ${ }^{2}$, Nuestra Carta Magna Provincial en el Art.174 1er. párr, que establece principios que rigen la administración pública provincial, entre los cuales se pueden destacar: el principio de eficacia, eficiencia, economicidad y oportunidad, centralización normativa, descentralización territorial, desconcentración operativa, jerarquía, coordinación, imparcialidad, sujeción al orden jurídico y publicidad de normas y actos ${ }^{3}$, apuntó el norte al cual debemos mirar.

De tal modo y en concordancia con tales fines, una de sus Instituciones - Registro General de la Provincia de Córdoba- para "aggiornarse" a este proceso de celeridad jurídica inmobiliaria ha llevado a cabo durante los últimos años, un descomunal esfuerzo en busca de afianzar los principios antes mencionados, ello aquí, que mediante diferentes resoluciones generales entre las que merecen ser destacadas la Res. $\mathrm{N}^{\circ} 1$ de fecha 18 de Marzo de $2015^{3}$, la Res. $N^{\circ} 11$ de fecha 5 de Agosto de $2013^{4}$ y la Res. $N^{\circ} 11$ del 29 de Octubre de $2012^{5}$, han logrado un verdadero proceso de descentralización y desconcentración del Estado, logrando así una mayor celeridad para los documentos ingresados, ya sean notariales, judiciales o administrativos.

Para más, la Ley Nacional 17.801 ha establecido en diferentes partes de su plexo normativo diferentes normas que buscan la celeridad del proceso.

\footnotetext{
${ }^{2}$ Sancionada con fecha Veinticinco de Marzo del año Dos Mil.

${ }^{3}$ Sancionada con fecha Veintiséis de Abril de Mil Novecientos Ochenta y Siete, reza en su Art.174, primer Párr.: "La Administración Pública debe estar dirigida a satisfacer las necesidades de la comunidad con eficacia, eficiencia, economicidad y oportunidad, para lo cual busca armonizar los principios de centralización normativa, descentralización territorial, desconcentración operativa, jerarquía, coordinación, imparcialidad, sujeción al orden jurídico y publicidad de normas y actos..."

${ }^{4}$ Dispone la desconcentración operativa hacia Delegación Villa María, ampliando las funciones asignadas.

${ }^{5}$ Dispone la desconcentración operativa hacia Delegación Río Cuarto, ampliando las funciones asignadas.
} 


\section{EL ARTÍCULO 6 DE LA LEY 10.432. MAS ALLA DE LAS PRERROGATIVAS OTORGADAS POR LA LEY NACIONAL REGISTRAL}

\section{2) LA RESERVA DE PRIORIDAD.}

Sin duda que no todo es celeridad, también debemos tener en cuenta la seguridad jurídica. De esto se encarga este famoso instituto o mecanismo que tanto reconocimiento recibió en nuestro país, por las naciones más civilizadas en el cuidado de la seguridad jurídica.

En materia de prioridades podemos distinguir entre la "llamada prioridad directa" de la “prioridad indirecta". La directa, como su nombre lo indica, la produce la presentación del mismo documento inscribible, considerando su día y hora de presentación 6 .

Ahora bien, en el artículo 25 de la ley 17.801 encontramos dos institutos relevantes: 1) por un lado la reserva de prioridad indirecta con efectos automáticos de preanotación y 2) la denominada retroprioridad plasmada en el art. 5 de la ley 17.801 , que permiten el más amplio espectro de tutela registral, protegiendo al documento no sólo desde su nacimiento, y hasta que llega al Registro, sino también en los momentos previos a la formalización del documento, constituyendo un mecanismo ágil que concilia adecuadamente los distintos intereses en juego, en procura de la seguridad jurídica.

La reserva de prioridad constituye el efecto jurídico que produce la certificación registral plasmada en el artículo 23 de la ley 17.801, que se materializa a través de su anotación en el folio respectivo, produciendo una garantía de inmutabilidad de la situación registral durante el plazo legal, respecto del documento para el que se la solicitó. Es decir, los negocios jurídicos no consumados o en gestión obtienen una oponibilidad condicionada a través de la mencionada reserva de prioridad indirecta emanada de las citadas certificaciones registrales. El documento que se otorgue ya sea de constitución, modificación o cesión de derechos reales sobre inmuebles, para gozar de dicha garantía debe autorizarse dentro del término de vigencia de la certificación art. 24 ley 17.801-, y presentarse en el plazo que le concede la ley. Cabe aclarar que

${ }^{6}$ Gabriel B. Ventura. Ley 17.801. Registro de la Propiedad Inmueble. Comentada. Anotada. Pág.124-125. 1 ed. Bs. As. Hammurabi, 2009. 


\section{EL ARTÍCULO 6 DE LA LEY 10.432. MAS ALLA DE LAS PRERROGATIVAS OTORGADAS POR LA LEY NACIONAL REGISTRAL}

dicha inmutabilidad es aplicable no solo respecto de los nuevos documentos que ingresen, a los que se les advertirá de la constancia del certificado, sino respecto del propio Registro.

Si bien en doctrina se habla de "cierre registral", ello no implica que se impida el acceso de otros documentos respecto del inmueble objeto del negocio jurídico, sino que ingresan y son anotados por el Registro con carácter condicional a las resultas de la presentación en término del documento autorizado. Si el documento no ingresa, o lo hace fuera de tiempo, retoma todo su vigor la registración condicionada, la que adquiere preferencia y plena validez desde la fecha de su ingreso, convirtiéndose en inscripción definitiva pura y constituyéndose, a su vez, en oponible para los posteriores documentos que ingresen.

\section{3)LA RESERVA DE PRIORIDAD Y SU DISTORSIÓN EN LOS PLAZOS DE VIGENCIA DEL CERTIFICADO.}

El Art.24 de la ley 17801 junto a los artículos 22, 23,25 y 26 regulan todo el mecanismo de la reserva de prioridad, al que se agrega el art.5 que establece la retroprioridad. Así, el Art. 24 reza: "El plazo de validez de la certificación, que comenzará a contarse desde la cero hora del día de su expedición, será de quince, veinticinco o treinta días según se trate, respectivamente, de documentos autorizados por escribanos o funcionarios públicos con domicilio legal en la ciudad asiento del Registro, en el interior de la provincia o territorio, o fuera del ámbito de la provincia, territorio o Capital Federal.

Queda reservada a la reglamentación local determinar la forma en que se ha de solicitar y producir esta certificación y qué funcionarios podrán requerirlas. Asimismo, cuando las circunstancias locales lo aconsejen, podrá establecer plazos más amplios de validez 


\section{EL ARTÍCULO 6 DE LA LEY 10.432. MAS ALLA DE LAS PRERROGATIVAS OTORGADAS POR LA LEY NACIONAL REGISTRAL}

para las certificaciones que soliciten los escribanos o funcionarios públicos del interior de la provincia o territorio". 7

Como vemos lo que tuvo en cuenta el legislador para fijar los plazos, fue la relación que había entre el domicilio del instrumentador y la sede asiento del Registro.

Así, si el instrumentador se encuentra en la misma ciudad asiento del Registro, el plazo será de quince días; si se halla domiciliado en otra ciudad, pero dentro de la misma provincia, el plazo será de veinticinco días; y si se encuentra domiciliado fuera de la provincia sede del Registro, el plazo será de treinta días.

Ahumada nos decía: “en el segundo párrafo de ese artículo se permite que las reglamentaciones provinciales establezcan plazos más amplios cuando ellas sean expedidas para ser utilizadas por funcionarios del interior de cada provincia; en consecuencia, las leyes locales sólo pueden ampliar el plazo de veinticinco días." 8

Esta prerrogativa no fe utilizada en la Ley Provincial Registral, y la cantidad de días de vigencia seguía siendo determinada únicamente por la Ley Nacional Registral. En correlación con lo antes dicho el Art. 43 del mismo cuerpo reza: "Las leyes locales podrán reducir los plazos establecidos en esta ley”.

Como ya lo decía García Coni, la ley 17801 es un ejemplo de federalismo ${ }^{9}$ puesto que la mitad de su articulado contiene remisiones a los ordenamientos locales. En este aspecto, el referido a los plazos, admite que las provincias, según las distintas configuraciones geográficas y las posibilidades de descentralización de sus oficinas registrales, adopten plazos más breves que los marcados supletoriamente por la ley nacional. En atención a la celeridad que se impone en los tiempos que corre, la ley nacional no admite plazos más largos, sino sólo abreviar los ya establecidos ${ }^{10}$.

Así por ejemplo en el art.28 de la ley 3394/71 de San Luis sí se hizo ejercicio de la opción, fijándose el plazo de veinte días para las certificaciones expedidas para ser

\footnotetext{
${ }^{7}$ Art. 24 Ley 17801. El Subrayado me pertenece.

8 Ahumada, Daniel E. Ley 5.771 Registral Inmobiliaria y Disposiciones Técnico-Registrales (comentada, concordada y anotada). Ed. Alveroni.

${ }_{9}^{9}$ García Coni, Raúl R.; "Procedimiento Inscriptorio"; Pág.28; Fundación Editorial Notarial; La Plata; 1981.

10 Scotti, Edgardo O.; "Derecho registral inmobiliario: modalidades y efectos de las observaciones registrales”; pág.164; Ed. Universidad 1980; Bs. As.
} 


\section{EL ARTÍCULO 6 DE LA LEY 10.432. MAS ALLA DE LAS PRERROGATIVAS OTORGADAS POR LA LEY NACIONAL REGISTRAL}

utilizadas en Villa Mercedes, manteniéndose en veinticinco días la vigencia para el resto del interior del territorio de esa provincia. Y el Art.36 de la ley 483/68 de la Pampa fijó en veinte días la vigencia para todas las certificaciones del interior de esa provincia.

Es decir, la vigencia de estos plazos no puede ser ampliada o modificada por ningún motivo, ni le son aplicables causales de suspensión, ellos caducan indefectiblemente en caso de no haber sido utilizados, al cumplirse la cantidad de días de su vigencia.

Estas prerrogativas no fueron utilizadas por la Ley Provincial Registral, hasta la sanción de la ley $10.432^{11}$, la que en un desacierto lógico y contrario a los grandes esfuerzos de celeridad realizados por todos los operadores del sistema jurídico inmobiliario, estableció en su Art. 6 lo siguiente: "Modifícase el primer párrafo del artículo 32 de la Ley N 5771 y sus modificatorias -Registro General de la Provincia-, el que queda redactado de la siguiente manera: "Las certificaciones requeridas al Registro General de la Provincia sobre el estado jurídico de los bienes y de las personas, según las constancias registradas, para la autorización de documentos relacionados con actos voluntarios de transmisión, constitución, modificación, cesión o extinción de derechos reales sobre inmuebles, conforme a lo dispuesto por el artículo 23 y siguientes de la Ley Nacional $\mathrm{N}^{\mathrm{o}}$ 17801, sólo pueden ser expedidas a petición de notarios, titular o adscripto de un Registro de la Provincia o funcionarios públicos de igual competencia. El plazo de vigencia de los certificados registrales será único y genérico de treinta (30) días corridos para la autorización de documentos notariales, judiciales o administrativos, a excepción del certificado registral para subastar y del certificado registral para la protocolización de planos por vía administrativa, que será en ambos casos- de ciento cincuenta (150) días corridos."

Como se observa se establece un plazo único y genérico de treinta días para los certificados registrales, dejándose exceptuado de dicho plazo el certificado registral para subastar y para protocolizar por vía administrativa, con lo cual se rompe con las

\footnotetext{
${ }^{11}$ Sancionada el treinta y uno de marzo de dos mil diecisiete.
} 


\section{EL ARTÍCULO 6 DE LA LEY 10.432. MAS ALLA DE LAS PRERROGATIVAS OTORGADAS POR LA LEY NACIONAL REGISTRAL}

prerrogativas otorgadas por la Ley Nacional Registral, yendo más allá de las facultades establecidas, las que sólo permiten la ampliación del plazo para aquellas certificaciones que van a ser utilizadas por funcionarios del interior de cada provincia. Asimismo, rompe con otro principio general sentado en el Art.43 de la Ley Nacional Registral, el cual concede la posibilidad de reducir los plazos por disposición de las leyes locales, con lo cual se distorsiona el funcionamiento de dicha institución.

\section{4).LA POSIBLE TACHA DE INCONSTITUCIONALIDAD FRENTE AL CASO CONCRETO}

$\mathrm{Si}$ bien corresponde a las provincias legislar en materia procesal, ya que ellas se reservan todo el poder no delegado a la nación -Art.121 C.N.-, por facultad del art.75 inc. 12 se le atribuye al Congreso dictar los códigos en materia civil, comercial, penal, entre otros, sin que tales códigos alteren las jurisdicciones locales.

Es decir, las provincias conservan todo lo que concierne a jurisdicción, al poder de imperium, por el cual crean sus propias instituciones.

En este sentido, en ningún caso se ha cuestionado, por ende, la existencia de normas procesales en los códigos ni en las leyes de fondo.

Así son numerosos los ejemplos de normas de fondo que contienen disposiciones procesales directrices, que resultan de aplicación obligatoria en todo el territorio de la Nación.

Como vemos, esto no es ajeno a esto Nuestra Ley Nacional Registral, que en diferentes partes de su plexo normativo establece diferentes plazos.

Vasta jurisprudencia existe sobre las facultades del Congreso Nacional de proceder en tal sentido, así se ha sostenido que “... las leyes de fondo pueden establecer normas procesales cuando deben integrar el instituto reglado por la ley nacional, sin que por ello afecten la competencia provincial para regular el proceso..."12. También se ha

${ }^{12}$ Cam. Apel. Bahía blanca, oct. 24 1972, L.L. 149.528. 


\section{EL ARTÍCULO 6 DE LA LEY 10.432. MAS ALLA DE LAS PRERROGATIVAS OTORGADAS POR LA LEY NACIONAL REGISTRAL}

dicho que: "... la carencia, en principio, de facultades del gobierno central para legislar en materia procesal, no impide la posibilidad de que algunas leyes de fondo contengan, al mismo tiempo, disposiciones de tipo procesal destinadas a garantizar las instituciones creadas por ellas mismas..."13. La Suprema Corte de la Provincia de Buenos Aires tiene dicho: “... cuando las Constitución Nacional confiere al Congreso las facultades de dictar la legislación de fondo le reconoce también la atribución de dictar normas procedimentales inherentes al funcionamiento de determinada institución, si lo estima preciso para que su esencia no resulte subvertida por las reglas procesales correspondientes a la legislación particular de cada provincia..."14.

No obstante a lo dicho, debemos tener en cuenta que el Art. 31 de Nuestra Constitución Nacional reza: "Esta Constitución, las leyes de la Nación que en su consecuencia se dicten por el Congreso y los tratados con las potencias extranjeras son la ley suprema de la Nación; y las autoridades de cada provincia están obligadas a conformarse a ellas, no obstante cualquiera disposición en contrario que contengan las leyes o constituciones provinciales, salvo para la provincia de Buenos Aires, los tratados ratificados después del pacto de 11 Noviembre de 1859 ".

Del presente artículo se desprende lo que se conoce como Jerarquía Constitucional, es decir hay una supremacía del orden jurídico federal sobre el derecho local. La Constitución Nacional asegura la supremacía de las leyes nacionales que se ajustan a ella, por corresponder al derecho federal tienen preeminencia sobre todo el derecho provincial, como lo establece el Art.31, que estructura un orden jerárquico, y es la fuente de la cual surgen las demás normas, leyes, decretos, resoluciones, etc. La supremacía del derecho federal -la C.N. y tratados internacionales suscriptos por la nación, leyes nacionales- se corrobora también en los artículos 5, 28 y 128.

\footnotetext{
${ }^{13}$ Cam. Apel. S. Isidro, nov. 8-966, L.L. 128- 782.

${ }^{14}$ Sup Corte Pcia. Bs. As. Junio 25-968, L.L. 133-964 - 8DJBA 84-270.
} 


\section{EL ARTÍCULO 6 DE LA LEY 10.432. MAS ALLA DE LAS PRERROGATIVAS OTORGADAS POR LA LEY NACIONAL REGISTRAL}

Es decir, en lo que a nosotros nos concierne la ley 10.432 en su Art.6 no hace otra cosa que ir en contra de la sustancia de la Ley Nacional Registral, que fijó en su Art.24 un plazo de vigencia para los certificados solicitados por escribanos y demás funcionarios, con la finalidad de mantener uniformidad en todo el territorio argentino, velando por la seguridad del tráfico jurídico inmobiliario y por su celeridad, a través del mecanismo de la Reserva de Prioridad.

Fue tan federal, como decía el Maestro García Coni ${ }^{15}$, la Ley Nacional Registral, que atendiendo a las distancias que padecían los escribanos públicos del interior de la provincia, facultó a los gobiernos locales a extender los plazos de las certificaciones solicitadas por ellos, buscando de esta forma un pie de igualdad entre aquellos que tenían sus notarías a escazas cuadras de la sede del Registro General de la Provincia. Por lo que opino que, llegado el caso, no le quedará otra opción a Nuestros Tribunales, que declarar la inconstitucionalidad del artículo 6 de la ley 10.432, atento a los fundamentos expresados durante el desarrollo de este trabajo.

\section{5) CONCLUSIONES}

El mecanismo de Reserva de Prioridad en nuestro Derecho Registral, cumple dos funciones fundamentales: una, ayuda a la seguridad del tráfico jurídico inmobiliario y dos, busca unificar el tiempo y la celeridad del mismo, para que sea uniforme en todo el país.

El Art. 6 de la ley 10.432 se encuentra en discordancia con todos los esfuerzos realizados por los distintos operadores del tráfico jurídico inmobiliario que van en busca de una mayor celeridad en sus operaciones.

\footnotetext{
${ }^{15}$ García Coni dice: "En el caso de la ley 17.801, la consideramos un ejemplo de federalismo, puesto que casi la mitad de su articulado contiene remisiones a los ordenamientos locales, especialmente en los arts. 9 y 38 referentes al contencioso registral”. Procedimiento inscriptorio. Pág.28. Fundación Editorial Notarial; La Plata;1981.
} 


\section{EL ARTÍCULO 6 DE LA LEY 10.432. MAS ALLA DE LAS PRERROGATIVAS OTORGADAS POR LA LEY NACIONAL REGISTRAL}

El Art.6 de la ley 10.432 es inconstitucional en virtud de lo establecido en el Art.31 de la Constitución Nacional Argentina.

Los plazos de vigencia de las certificaciones, más que ser ampliados deberían ser reducidos, atento a la gran desconcentración y descentralización del Registro General de la Provincia, no sólo a través de la creación de Delegaciones en el Interior de la Provincia, sino también por la implementación del Certificado Registral vía Web.

\section{6) BIBLIOGRAFÍA.}

AHUMADA, Daniel E. Ley Registral Inmobiliaria 5771 y disposiciones técnicoregistrales (comentada, concordada y anotada) Ed. Alveroni.

GARCÍA CONI, Raúl R. Procedimiento Inscriptorio. Fundación Editorial Notarial; La Plata; 1981.

SCOTTI, Edgardo O. Derecho registral inmobiliario: modalidades y efectos de las observaciones registrales; Ed. Universidad 1980. Bs. As.

VENTURA, Gabriel B. Ley 17.801. Registro de la Propiedad Inmueble. Comentada. Anotada. Ed. Hammurabi. 